J. Management and Humanity Research

Vol. 6, 2021, 1-17

ISSN: 2582-7766 (online)

Published on 1 August 2021

Journal of

www.researchmathsci.org

DOI: http://dx.doi.org/10.22457/jmhr.v06a012129

Management and

Humanity Research

\title{
Demand Analysis of IMIS Professionals Based on Online Recruitment Website Data
}

\author{
Liu Shi* \\ Department of Economics and Management Professional Degree Education Center \\ East China Normal University \\ Shanghai - Shanghai, China -200241. Email: Lscrazystone@163.com \\ Received 1 May 2021; accepted 26 July 2021
}

\begin{abstract}
In order to cope with the data-driven social environment, enterprises and social organizations in the process of informatization development have a sharp increase in the demand for informatization professionals. Therefore, how to meet the needs of information society for the specialization, compound and diversification of IMIS personnel has gradually become a research hotspot. Using text mining methods to obtain relevant information management and information systems professional recruitment data, again from the social structural demand, professional demand multiple dimensions of unit of choose and employ persons in the job market overall demand to conduct a comprehensive analysis of the fuse professional, to understand the fuse professional talents of overall employment situation and enterprise to fuse professional recognition. Finally, with demand as the orientation and students as the main body, the author puts forward suggestions on the development of IMIS professionals.
\end{abstract}

Keywords: information management and information system, text mining, visual analysis

\section{Introduction}

With the advent of the Internet era, information resources have become an important strategic resource and means of production. The deepening degree of informatization also accelerates the transformation of social division of labor and industrial structure, which affects the supply and demand relationship between enterprises in various industries and talents in colleges and universities.

In order to cope with the data-driven social environment, enterprises and social organizations in the process of information reform have a sharp increase in the demand for information professionals. However, at present, the social demand for information professionals is strong but the overall employment quality of students is not high. Taking 


\section{Liu Shi}

information management and information system as an example, the specialized courses cover a wide range of areas, including computer, economic management, mathematical statistics, etc., and various colleges and universities set up different departments and train different emphases [1]. Due to the variety of courses, the students' energy is limited, which leads to the students' knowledge is broad but not good, and they can't find the direction of future development.

The employment of college students has always been a topic of general concern in all walks of life. The ultimate goal of professional education is to meet the needs of social development and to provide professional and highly compatible talents for enterprises and institutions. Therefore, how to meet the needs of information society for the specialization, compound and diversification of IMIS personnel has gradually become a research hotspot. This research through the crawl recruitment website recruitment information relating to the fuse professional talents, concrete analysis in the form of text mining the advertisement demand, help fuse professional students to understand the real demand of enterprises, to master professional development direction, at the same time fuse professional curriculum for colleges and universities to provide reference for developing and perfecting education system.

\section{Literature review}

Scholars at home and abroad have conducted a lot of research and analysis based on the specialty of information management and information system, and put forward multidimensional improvement ideas for the development and training of professional talents.

\subsection{Foreign research status}

The major of information management and information system originated from the United States. Since 1968, researches related to information management began to appear and papers related to the major of information science have been written successively (Claver E, 2000) [2]. At first, Management Information System MIS was only regarded as a research direction without clear relevant explanation, and did not attract academic attention. It was not until 1970 that the category of "Management Information System" was first proposed (Zhang Shimin, 2002) [3]. However, in 1980, Professor Golden B. Davis from Carlson School of Management, University of Minnesota gave a clear definition of MIS: a subject that "uses computers for information processing, management and decision making" (Yue Jianbo, 1999) [4]. As a result, he became the founder of Management Information Systems. It can be said that the major of information management and information system is the product of social informatization. It combines 


\section{Demand Analysis of IMIS Professionals Based on Online Recruitment Website Data}

management science, computer science, organization science and other disciplines, and is a new discipline that uses information technology to solve the problems of production management [5-6]. At the end of the 1980s, information management and information system research also expanded rapidly as a computer application major, and universities in various countries have set up undergraduate and master programs of this subject. How to train MIS professionals in line with the development of The Times and maintain the uniqueness and vitality of this major has also become a research hotspot of foreign scholars.

\subsection{Domestic research status}

With the close communication of scholars at home and abroad, the concept of information management has been introduced into China. The Ministry of Education promulgated the Catalogue of Undergraduate Majors of Regular Institutions of Higher Learning in 1998. [7] The major of Information Management and Information System was established. With the continuous exploration of various colleges and universities according to their own characteristics, the IMIS major has mainly developed three types of talent training paths: technology, management and compound [8]. According to the literatures on CNKI, the earliest retrieved article on the information management major was Reflections on the Implementation of the New Major of "Information Management and Information System" published in Library Industry in 1999. This paper analyzed the fuzzy concept of the information management major and discussed how to do a good job of this emerging major [9]. In the subsequent literature, a large number of scholars have analyzed the current situation of talent demand and disciplinary reform measures for information management and information system specialty from various aspects, which can be divided into the following types according to research methods:

\section{Qualitative research on IMIS professionals}

Lijuan (2009) [10] Guided by the demand of talent market, the curriculum system of IMIS professional support is constructed through four ability levels: basic professional ability, comprehensive professional ability, core professional ability and professional competitiveness. Huiyan (2011) [11] the evaluation index system of employment competitiveness of IMIS major students is constructed from three aspects of personal ability, comprehensive quality and professional ability. Analytic Hierarchy Process (AHP) is used to analyze each index in detail, and the influence results of specific competitiveness factors are obtained. Zhengshan [12] In order to cope with the environmental background of Internet + , through investigation and practical application, 


\section{Liu Shi}

this paper proposes an innovative practical teaching reform system with students as the main body and "application-practice-innovation" as the main line. Hao (2020) [13] through the interview method and using Nvivo 10 text analysis software to conduct qualitative research on the interview results, the problems existing in the information management major under the new engineering background were understood.

\section{Quantitative research on IMIS professionals}

Wenjie (2009) [14] through the manual screening of the recruitment information for IMIS personnel on the recruitment website, the content analysis method is used to reveal the skills requirements of related enterprises for IMIS personnel. Jiang (2009) [15] through the statistics of college enrollment network data, summed up the employment flow and development prospects of IMIS professionals. Tianbao (2018) [16] based on Nolan model, this paper analyzes the change of employment market and the corresponding talent demand of IMIS specialty in different stages of informationization in China. He (2020) [17] through online questionnaires and information collected and sorted from recruitment websites, the skill requirements of employers for students majoring in information management and the problems encountered by graduates in the process of job hunting were understood.

\section{Collect data on negative reviews}

\subsection{Data selection}

The selection of data sources will directly affect the authenticity, comprehensiveness and accuracy of recruitment data, which is of great importance for further research in the future. At present, the development of online recruitment platforms is diversified, forming a competitive pattern of recruitment field, recruitment comprehensive, and recruitment channel. The specific platform information is shown in Table 1. According to the "2020 China Online Recruitment Industry Market Development Research Report" published by iResearch Consulting [18]. It can be seen that there are a wide variety of recruitment platforms in various forms. Among them, the recruitment platforms in the fields of hunting, vein and hook mainly concentrate on their own fields, and the industries are more vertical, with great differences among platforms. On the other hand, the new channel recruitment platform disperses the user traffic and the recruitment information is not concentrated enough. In contrast, Zhaopin, 51job.com and other comprehensive recruitment platforms have a large number of enterprises and a wide range of information sources, which can meet the recruitment needs of different industries and different job seekers. Therefore, they are more suitable as the research object of this paper. 
Demand Analysis of IMIS Professionals Based on Online Recruitment Website Data

Table 1: Comparison of various types of recruitment platforms

\begin{tabular}{c|c|c}
\hline $\begin{array}{c}\text { Type of recruitment } \\
\text { platform }\end{array}$ & A typical platform & The characteristics of \\
\hline Integrated platform & Zhaopin.com, 51job.com & $\begin{array}{c}\text { Preferred to comprehensive } \\
\text { recruitment, involving various } \\
\text { industries }\end{array}$ \\
\hline Domain Platform & Hunting, pulse, pull hook & $\begin{array}{c}\text { Different platform characteristics } \\
\text { are large, the industry is more } \\
\text { vertical }\end{array}$ \\
\hline Channel platform & $\begin{array}{c}\text { Public number job platform } \\
\text { The enterprise establishes the } \\
\text { platform by itself }\end{array}$ & $\begin{array}{c}\text { The form is rich, the platform is } \\
\text { many, relatively scattered }\end{array}$ \\
\hline
\end{tabular}

On the other hand, by comparing the top three comprehensive recruitment platforms in terms of market share: Zhaopin.com, Qiaopu.com and Boss Zhipin, we find that Zhaopin.com has a special campus recruitment section, which is more suitable for the research objects of this paper's fresh graduates.

To sum up, Zhaopin has a good representation among recruitment websites, and its website content is more in line with the text mining needs of this study, so this paper selects Zhaopin as the research data source.

\subsection{Data capture}

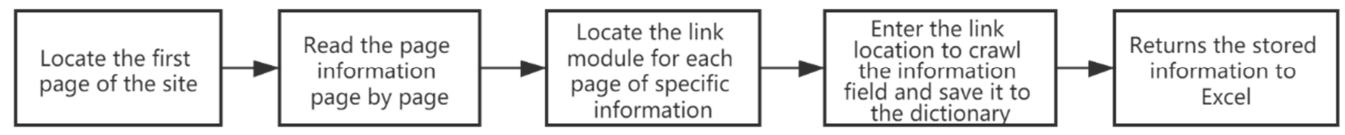

Figure 1: Flowchart of data capture

After determining the data source for this study, the recruitment data crawling method should also be determined. This paper uses Python language to crawl data.Based on "information management and information system", "fuse", "information management", "information system" as the key words to get to the information management and information systems professional related recruitment information, specific crawl field has "jobs", "region", "degree", "job description", "enterprise name", "industry", "enterprise", this set of data will be used for the fuse enterprise type of talent employment, job conditions, such as skill requirements for detailed analysis, to determine fuse professional talented person's employment status and enterprise information management and information systems professional recognition and awareness. The detailed process of crawling data in Python is shown in Figure 1. 
Liu Shi

\subsection{Data Preprocessing}

Data preprocessing is an important step before formal text analysis. In this paper, the crawled recruitment data is cleaned to obtain 1,969 valid recruitment data.Then, as shown in Figure 2, Chinese word segmentation, word frequency statistics and other data preprocessing methods are used to extract the implicit information in the text.

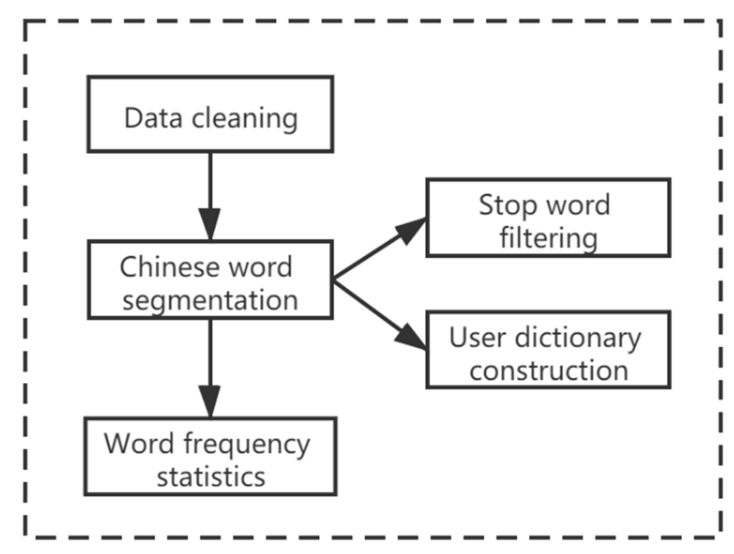

Figure 2: Data preprocessing flow chart

\section{Analyze talent demand based on recruitment data}

\subsection{Structural requirements}

This paper focuses on the social structural demand, from regions, industries to enterprises, positions, from macro understanding to micro analysis, step by step analysis of the social components of the overall demand for IMIS personnel.

\subsubsection{Regional distribution}

Through the analysis of the regional distribution of enterprise recruitment, as can be seen that the top provinces and cities with large demand for IMIS professionals are Beijing, Guangdong, Jiangsu, Shandong, Henan, Shanghai and Zhejiang. Most of these provinces and cities are geographically advantageous and economically developed regions, which offer more job opportunities and are more attractive to graduates. However, there is less demand for jobs in the southwest, northwest and northeast of China, and their attractiveness to IMIS professionals is also low.

\subsubsection{Industry distribution}

In the job market, the industry you work in is crucial to the job seeker, and determines the general development direction of the future. Therefore, understanding the job 
Demand Analysis of IMIS Professionals Based on Online Recruitment Website Data requirements of the IMIS major will help the IMIS talents to clarify their development goals and grasp their learning direction. As shown in Figure 3, after classifying the industry information of the recruitment data, the top 10 data of the industries are extracted from the 37 industries. It can be seen that the IT service/Internet/computer software industry takes up the highest proportion, followed by the communication/ network equipment industry, indicating that the information management major has trained more technical talents, which is in line with the trend of the current era of rapid development of the Internet. It is followed by real estate/construction/building materials, training/extracurricular education/educational counseling, consulting services/ professional technical services, both the old real estate industry and the emerging education industry, which shows that the IMIS major keeps pace with the development of The Times and occupies a dominant position in the ever-changing employment environment.

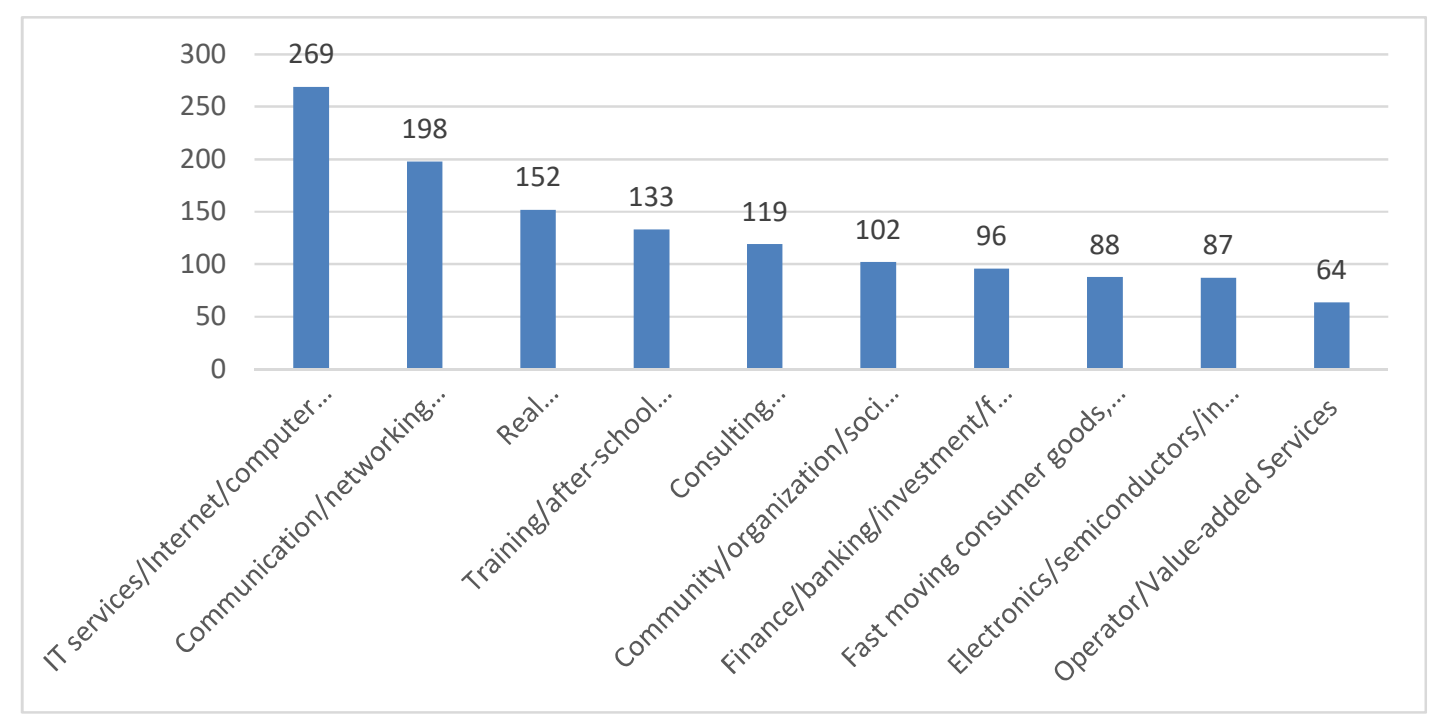

Figure 3: Top 10 industry distribution of enterprises

\subsubsection{Distribution of enterprise ownership}

It can be seen from Figure 4 that the recruitment of IMIS professionals is mainly in private enterprises (43\%), followed by state-owned enterprises (25\%), joint-stock enterprises (10\%), listed companies (8\%) and public institutions (6\%), while joint ventures (3\%), wholly foreign-owned enterprises (2\%), state organs (1\%) and other enterprises account for a relatively low proportion of recruitment positions. According to the National Bureau of Statistics, it can be seen that in 2019, the ratio of employees in state-owned enterprises, public institutions and private enterprises is close to 1:3. As can 
Liu Shi

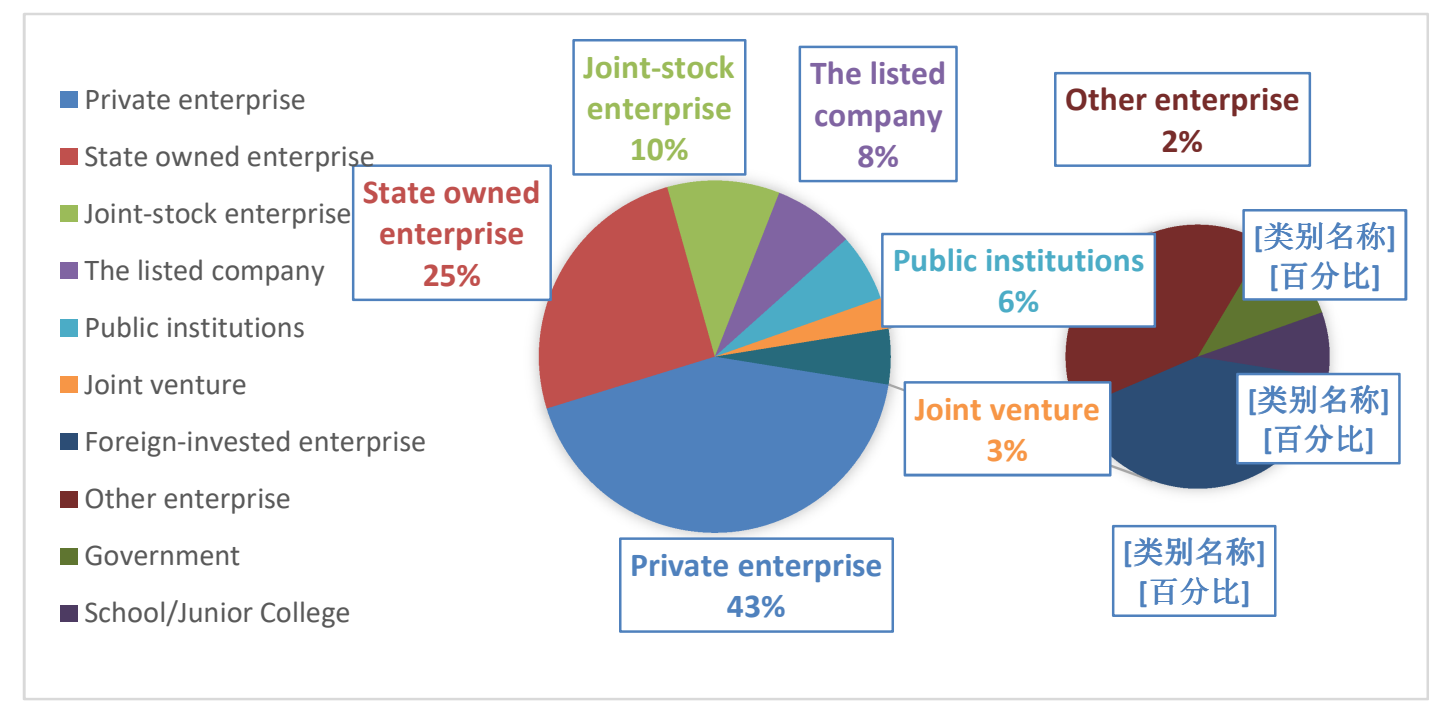

Figure 4: Distribution diagram of enterprise nature

be seen from Figure 4, the ratio of employees in state-owned enterprises, public institutions and private enterprises in related recruitment positions of IMIS major is about $3: 4$. By comparison, it can be seen that the proportion of recruitment of IMIS professionals by state-owned enterprises and public institutions has increased significantly, indicating that they have a relatively high degree of recognition and recognition of IMIS professionals. The large base of private enterprises leads to the large demand, which still provides a large number of jobs for IMIS professionals.

\subsubsection{Distribution of post types}

Table 2: Position system of IMIS personnel

\begin{tabular}{cccc}
\hline Job category & Specific jobs & jobs & Accounted for \\
\hline technical & The development of & 282 & $14.32 \%$ \\
& test & 17 & $0.86 \%$ \\
& operations & 129 & $6.55 \%$ \\
& algorithm & 8 & $0.41 \%$ \\
& $\begin{array}{c}\text { Network security } \\
\text { hardware }\end{array}$ & 59 & $3.00 \%$ \\
& Data development and & 21 & $1.07 \%$ \\
& analysis & 65 & $3.30 \%$ \\
\hline Management class & subtotal & 581 & $29.51 \%$ \\
& GuanPeiSheng & 61 & $3.10 \%$ \\
& The consultant & 71 & $3.61 \%$ \\
& The project & 133 & $6.75 \%$ \\
& management & & \\
& Integrated & 11 & $0.56 \%$ \\
\hline
\end{tabular}


Demand Analysis of IMIS Professionals Based on Online Recruitment Website Data

\begin{tabular}{cccc}
\hline & $\begin{array}{c}\text { File management } \\
\text { Information }\end{array}$ & 75 & $3.81 \%$ \\
& management & 363 & $18.44 \%$ \\
\hline & subtotal & 714 & $36.26 \%$ \\
\hline Product Operation & The product manager & 22 & $1.12 \%$ \\
& operating & 39 & $1.98 \%$ \\
& Customer service & 16 & $0.81 \%$ \\
\hline Marketing and Sales & subtotal & 77 & $3.91 \%$ \\
& sales & 73 & $3.71 \%$ \\
& Marketing/Marketing & 30 & $1.52 \%$ \\
& The supply chain & 10 & $0.51 \%$ \\
\hline Functional class & subtotal & 113 & $5.74 \%$ \\
& The human resources & 66 & $3.35 \%$ \\
& administrative & 126 & $6.40 \%$ \\
& financial & 9 & $0.46 \%$ \\
& accounting & 13 & $0.66 \%$ \\
& Teachers' & 32 & $1.63 \%$ \\
& clerk & 45 & $2.29 \%$ \\
\hline other & subtotal & 291 & $14.78 \%$ \\
\hline A total of & & 193 & $9.80 \%$ \\
\hline
\end{tabular}

Knowing the job types of enterprises in advance can help IMIS professionals to position themselves for career development, learn relevant technologies in a targeted way, and deliver suitable jobs.

The recruitment information of an enterprise usually has multiple descriptions of a position. This study, by referring to the relevant job classification literature and sorting out the job information in the recruitment data, established the IMIS personnel position system, including 5 level-one positions and 25 subdivided positions. The specific information is shown in Table 2. The five first-level positions are: technology, management, product operation, marketing and sales, and functional. Among them, management positions accounted for $36.26 \%$; Followed by technology, accounting for $29.51 \%$; The positions of functional, marketing and product operation are relatively small, accounting for about $10 \%$.

Through further analysis, the top five positions are: information management, development, project management, operation and maintenance, and administration. Information management positions are in the largest demand, with 363 positions, accounting for $18.44 \%$, which is consistent with the direction of information management major to cultivate information professionals. Development posts followed with 282 posts, accounting for $14.32 \%$. This indicates that with the development of the Internet, the recruitment market has a great demand for technical development talents, and enterprises also attach great importance to the technical development ability of IMIS professionals. 


\section{Liu Shi}

Then there are 133 job information for project management, accounting for $6.75 \%$, which indicates that IMIS talents who attach equal importance to management and technology have a high degree of compatibility with project management.

\subsection{Requirements for professional competence}

After analyzing the social structural demand, this study starts from the talent itself to have a deep understanding of the employers' demand for the diploma and professional ability of graduates majoring in IMIS.

\subsubsection{Educational requirements}

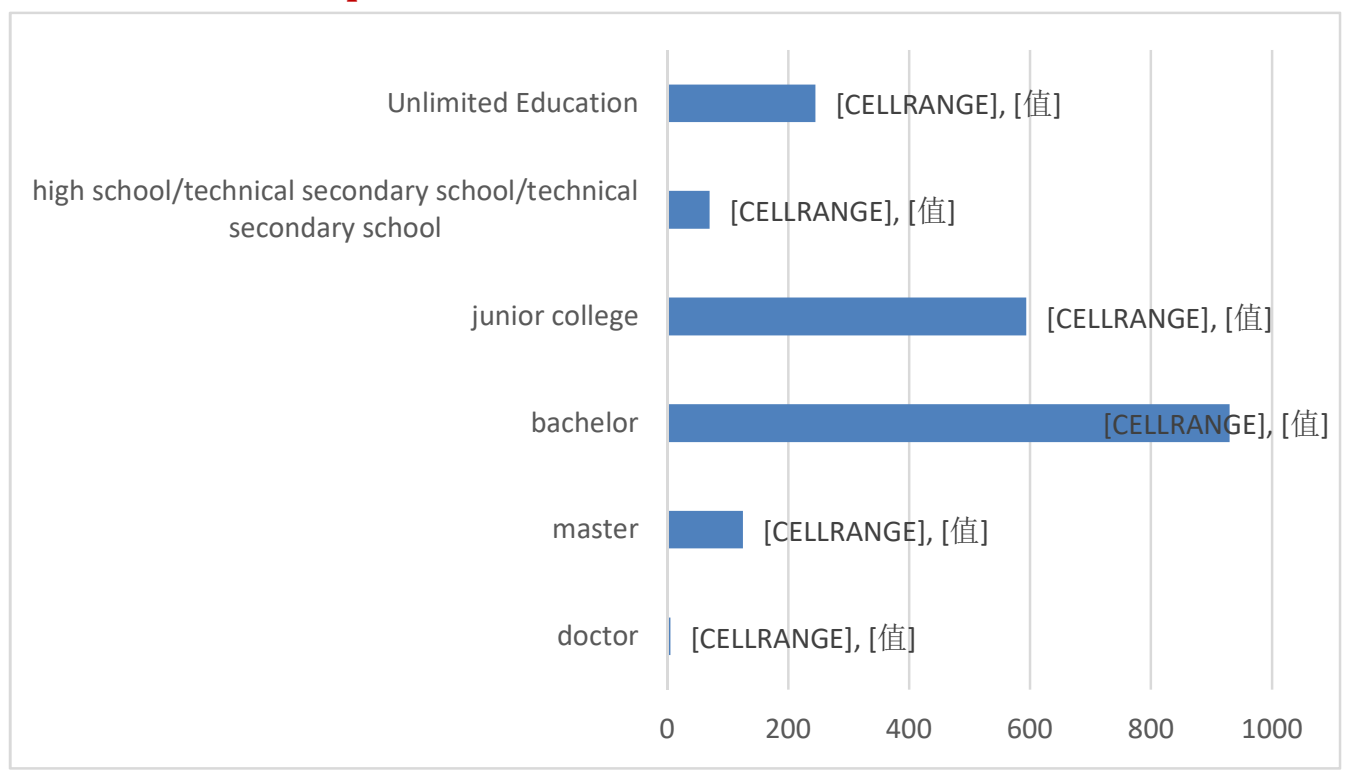

Figure 5: Distribution diagram of enterprise education demand

Educational background is the threshold for most enterprises to recruit. Understanding the demands of different enterprises for different educational background can help IMIS talents to understand the current job market, timely plan their own education and employment plans, and improve their employment competitiveness.

After classifying and summarizing the fields of educational background, as shown in Figure 5, it can be concluded that the educational background requirements of enterprises can be divided into the following categories: doctor's degree, master's degree, bachelor's degree, junior college degree, high school/technical secondary school/technical secondary school. Nearly $90 \%$ of enterprises have mandatory educational background requirements, and there are 245 positions with no limitation of educational background, accounting for only $12.4 \%$. Among them, the demand for jobs with a bachelor's degree 
Demand Analysis of IMIS Professionals Based on Online Recruitment Website Data

was the highest, accounting for 47.2 percent, or 930.It is followed by junior college (30.2\%), master's (6.3\%), high school/technical secondary school/technical secondary school (3.6\%), and doctor's degree, which is only 5 positions, accounting for $0.3 \%$.

For further analysis of education information, as shown in figure 6, in terms of nature of enterprise, state-owned enterprises and institutions of higher degree required, most require bachelor's and master's degree or above, recruitment in the data of only five requirement doctoral degree positions were all from institutions and state-owned enterprises, at the same time, these five are the high-end technology job, higher demands on personal skills. In terms of enterprise scale, large enterprises tend to recruit bachelor's degree and master's degree or above, while small and medium-sized enterprises do not have high requirements for education, most of which require college degree or above.

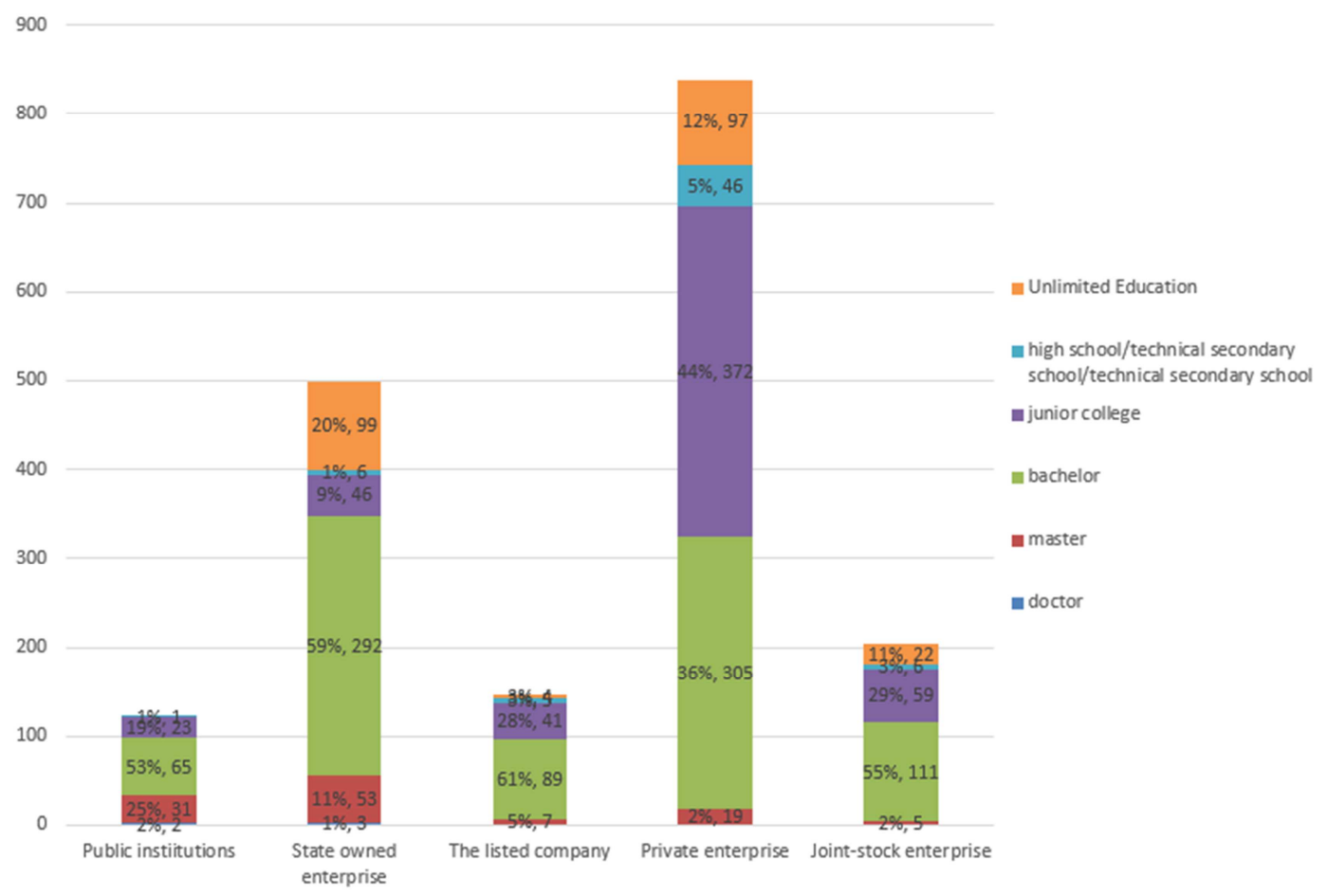

Figure 6: Distribution diagram of educational requirements of various types of enterprises

\subsubsection{Basic capability requirements}

For the basic abilities, this paper summarizes the basic competence of IMIS professionals required by enterprises and establishes the framework of the basic competence system of IMIS talents, as shown in Table 3. 


\section{Liu Shi}

Table 3: Framework of basic ability system for IMIS personnel

\begin{tabular}{ccc}
\hline Level indicators & $\begin{array}{c}\text { The secondary } \\
\text { indicators }\end{array}$ & frequency \\
& The sense of & 581 \\
& responsibility & \\
& Logical ability & 208 \\
Professional quality & Executive force & 128 \\
& Professional dedication & 121 \\
& Writing ability & 65 \\
& Secrecy consciousness & 38 \\
\hline \multirow{3}{*}{ Personality traits } & Meticulous carefully & 461 \\
& active & 312 \\
& Steadfast patience & 269 \\
& Bear hardships and stand & 210 \\
& hard work & 98 \\
\hline Interpersonal & affinity & 794 \\
communication & Team collaboration & 405 \\
& Presentation skills & 141 \\
& Organizational & 372 \\
\hline The physical and mental & leadership & 95 \\
\hline quality & Compressive ability & 248 \\
\hline \multirow{2}{*}{ Gange requirements } & Good temperament & 73 \\
\hline
\end{tabular}

As can be seen from Table 3, the framework of the basic ability system for IMIS professionals is mainly composed of 5 first-level indicators and 18 second-level indicators, which generally contains the basic ability demands of employers for IMIS talents in all aspects. The first-level indicators include the following aspects: professional accomplishment, character characteristics, interpersonal communication, physical and mental quality, and language requirements. Among all the secondary indicators, the ability of teamwork is mentioned the most times. In the era of rapid development of the Internet, the work form cannot be separated from close communication and cooperation, so the ability of collaboration and communication is extremely important in the normal situation of a team. The second is responsibility, meticulous and serious, which shows that the enterprise attaches great importance to the serious attitude of employees to the person in charge of work. The ability to express oneself is also a quality that is highly valued by enterprises. One of the important skills that applicants should have is the ability to be good at communicating and expressing their own opinions in team cooperation. Under the index of physical and mental quality, the ability to work under pressure is mentioned many times, which indicates that with the rapid flow and development of various industries, the ability to work under pressure has become an 


\section{Demand Analysis of IMIS Professionals Based on Online Recruitment Website Data}

essential trait for job seekers to meet future challenges and help enterprises expand their territories. According to the nature of industry and jobs were analyzed, and the third industry, service industry most jobs will have to have affinity, good temperament, Internet related position and file management related requirements for applicants confidential consciousness, most foreign companies are clear job seekers have certificates of English band 4 and band 6 and have good listening, speaking, reading and writing.

\subsubsection{Professional skills requirements}

In the process of professional skills analysis, the professional skills of the IMIS major are divided into three categories: system development skills, data processing skills and management decision-making skills. The specific skill requirements of each category are summarized, and the statistical results of secondary indicators of the skill category are obtained, as shown in Table 4.

Table 4: Framework of professional skills system for IMIS personnel

\begin{tabular}{ccc}
\hline Level indicators & The secondary indicators & frequency \\
\hline & Demand analysis & 139 \\
& The system design & 177 \\
& Software development & 324 \\
System development skills & Software testing & 104 \\
& Network security & 137 \\
& Basic Computer & 248 \\
& Knowledge & 366 \\
& The database & 99 \\
& Data mining & 131 \\
Data processing skills & The data analysis & 328 \\
& Information management & 128 \\
& The project management & 74 \\
& Promotion planning & 102 \\
& Copy editor & 114 \\
Managerial decision & ERP & 44 \\
making skills & The electronic commerce & 179 \\
\hline
\end{tabular}

In the module of system development skills, enterprises have the highest requirements for software development ability, including the requirement for IMIS personnel to master programming languages such as Java, C++, Python, HTML, CSS, etc., which indicates that there is a high demand for software development in the recruitment market, and IMIS personnel who master development skills will have an advantage in the recruitment market. Secondly, employers also put forward certain requirements on the basic computer knowledge of job seekers, which indicates that learning computer network, data structure, operating system and other basic computer 


\section{Liu Shi}

knowledge is the key requirement for IMIS professionals who want to engage in technical development.

In the module of data processing skills, database is a skill most required by enterprises, including the requirement of IMIS personnel to master databases such as ACCESS, Mysql, SQL Server, skilled application of SQL language and the establishment and maintenance of data warehouse. In the era of data explosion, enterprises have higher requirements on the data processing ability of job seekers. They are not limited to the processing of simple data, but proficient in the application of database technology and data mining methods to conduct in-depth analysis of data, so as to obtain useful information for management and application.

In the module of management and decision-making skills, a good command of office software is still the basic requirement for job applicants, while knowing ERP related processes, having good copywriting and planning skills, and understanding ecommerce knowledge are other skills requirements for IMIS personnel.

\section{Suggestions on the cultivation of IMIS talents under the guidance of demand}

Text visualization based on above analysis, this paper focuses on fuse talent comprehensive, balanced and sustainable development, put forward the following three Suggestions, will demand oriented education concept in information management and information systems professional teaching, improve the fuse professional students' personal ability and comprehensive quality, can meet the needs of times development, continuous delivery of high quality for the society information management and information systems professionals.

\subsection{Defining professional training objectives to improve students' ability of career planning}

With the development of The Times, the job market has put forward many new demands on job seekers. Keeping up with the trend of The Times and clarifying the training objectives of IMIS major can help students make career plans in advance and enhance their competitiveness in employment. According to the recruitment information survey results, the rapidly developing emerging industries have a large demand for informationrelated majors. However, due to the hybridization of management and technology of the IMIS major, students do not know about the available positions and do not know their own positioning at the early stage. Schools should increase lectures on cutting-edge technologies in the industry and on employment development to help students keep abreast of the latest achievements in discipline and social development. At the same time, 


\section{Demand Analysis of IMIS Professionals Based on Online Recruitment Website Data}

in the aspect of curriculum setting, we should keep the leading edge of The Times, shorten the updating cycle of curriculum setting, and actively introduce new theories and new technologies to make the new curriculum coexist with the traditional curriculum.

From hiring data can see, the job market to fuse the talent requirements of technical master ability improved, in addition to system development skills, information processing skills to be the core of the fuse talent ability, can skilled use of database technology, the information collection, processing, deep mining and analysis of management professionals are more popular with the enterprise. Therefore, at the present stage, while paying attention to the ability cultivation of management decision-making and system development, courses related to information processing ability of IMIS specialty can be adjusted appropriately to strengthen the cultivation of information technology-related knowledge. , of course, the school curriculum should strictly control the scale, pay attention to their aptitude, to enhance the employment competitiveness of students, also should pay attention to the students' interest in personal development, all kinds of professional ability of form a complete set of scientific research and teaching research emphasis, lets the student in system development, data processing, management decision has an opportunity to choose interest in three ways.

\subsection{Improve the practical teaching system and strengthen students' practical} operation ability

Due to the requirement of the discipline itself to information technology, strong practicality is one of the characteristics of the program. Through the recruitment information survey results, employers in addition to the educational background, professional knowledge of the basic aspects of rigid requirements, also put forward specific requirements on the practical ability of applicants. Most companies require job applicants to have hands-on project experience, while a few require internship experience in a relevant position. Therefore, in combination with the actual needs of talent cultivation in IMIS major, we should constantly improve the practical teaching system and strengthen the practical operation ability of students in IMIS major.

In terms of curriculum setting, we should perfect the training system of experimental courses and emphasize students' practical ability. In addition to the basic compulsory experiment course, elective experiment courses in all kinds of professional ability, such as open software development and design experiment in system development, both to ensure advancement in technology, and to ensure continuity and overall importance in the curriculum, let the students theoretical knowledge combined with a thorough understanding of the entire software development process; In terms of data processing, practical courses such as commercial data analysis and operation can be offered. In terms 


\section{Liu Shi}

of management decision, ERP sand table simulation and other experimental courses can also help students quickly understand the relevant knowledge of enterprise intelligent management.

In manufacture-learning-research cooperation, the school should improve the ability of organization, create more practice opportunities for students, such as seriously organize the student enrollment at all levels related data analysis, program development, algorithm design, the support team, students' scientific research studio, active contact willingness to cooperate with the school of enterprise, to arrange related projects and internships for students. This not only promotes the innovative development of enterprises, but also enriches students' practical experience and enhances students' practical operation ability.

\subsection{Enrich campus extracurricular activities to cultivate students' good physical} and mental quality and ability of personalized development

In modern society, products, models, formats, and even organizations are constantly innovating, and various industries are also constantly seeking to deepen reform. Therefore, in today's society, employers prefer job seekers with good physical and mental qualities and personalized development who can resist pressure, adapt quickly, and help enterprises meet challenges and expand the frontier. According to the recruitment information analysis results, employers have a good ability to resist pressure, can embrace change, personality development put forward clear requirements.

Campus rich extracurricular activities, not only limited to sports, literature and art competitions, debates, etc., can also be combined with multimedia, electronic commerce emerging industries such as the introduction of new activities, both enrich the students' extracurricular life, and give them a show ego, to express themselves and communicate with the outside world and cooperation opportunities, their personal development space, not only conforms to the requirements of the Ministry of Education of contemporary college students' physique and comprehensive development, and achieve the personalized look forward to in the development of enterprises for job seekers.

\section{REFERENCES}

1. Jiang Yong and Ma Caixue, Research on the specialty development of information management and information system, Higher Agricultural Education, 2 (2004) 5154.

2. E.Claver, R.Gonzalez and J.Llopis, An analysis of information systems (1981-1997), Information \& Management, 37(4) (2000) 181-195. 
Demand Analysis of IMIS Professionals Based on Online Recruitment Website Data

3. Zhang Shemin and Liu Min, Discussion on the development and teaching of information management and information system, Statistics \& Information Forum, 4 (2002) 70-74.

4. Yue Jian Bo, Information Management Basis, Beijing: Tsinghua University Press, 1999.

5. G.B.Davis and M.H.Olson, Management Information Systems: Conceptual Foundation, Structure and Development (2nd ed.), New York: McGraw - Hill, 1984.

6. G.W.Dickson and G.DeSanctic, Information Technology and Future Enterprise, New Jersey: Prentice - Hall, 2000.

7. Common institutions of higher learning undergraduate major directory and professional introduction, Beijing: Higher Education Press, 1998

8. Chen Yanshou, Reflections on several issues of information management and information systems specialty construction, Journal of Information, 8 (2006) 140142.

9. Su Ruizhu, Reflections on the implementation of the new specialty of information management and information systems, Library Science, 2 (1999) 8-12.

10. Yu Lijuan, Research on application talents training based on competence framework - taking information management and information system as an example, Science and Technology Management Research, 29(5) (2009) 360-362..

11. Huang Shuwei and Liu Huiyan, Research on the evaluation factors of employment competitiveness of students majoring in information Management and Information System, Journal of Shenyang Normal University (Natural Science Edition), 29(3) (2011) 365-368.

12. Luo Zhengshan, Zhang Xinsheng and Wang Xiaowan, Research on the practice teaching system of information management and information system under the background of Internet, Journal of Xi 'an University of Architecture and Technology (Social Science Edition), 35(6) (2016) 92-96.

13. Xu Hao, Xie Chunyan, Wang Zihao and Deng Sanhong, Research on the ability improvement strategy of students majoring in information management and information systems under the background of new engineering: based on the exploration of the ground theory, Books \& Information, 6 (2020) 35-45.

14. Cai Wenjie, Li Yue, Wang Weijun and Ding Jielan, Information management and information system major undergraduate talent market demand analysis based on online recruitment content analysis, Journal of Library Science, 31(8) (2009) 18-20.

15. Jiang Ling, Yang Yi and Diao Jian, Information management and information system professional positioning and training direction analysis, Information Management and Information Systems, 32(4) (2009) 41-43.

16. Tse, White Smile, Research on the employment demand and talent training mode of information management and information system under big data environment, Employment of Chinese College Students, 16 (2018) 58-64.

17. LI He, Training reform of applied talents in IMIS major under the background of integration of industry and education, Journal of Hainan Normal University (Natural Science Edition), 33(2) (2020) 231-237.

18. Research Report on the Market Development of China's Online Recruitment Industry in 2020, 2020. 